\section{Ritonavir inhibits HIF-1 $\alpha$-mediated VEGF expression in retinal pigment epithelial cells in vitro}

\begin{abstract}
Purpose Retinal hypoxia-mediated activation of the hypoxia-inducible factor (HIF pathway) leading to angiogenesis is a major signaling mechanism underlying a number of sight-threatening diseases. Inhibiting this signaling mechanism with an already approved therapeutic molecule may have promising anti-angiogenic role with fewer side effects. Hence, the primary objective of this study was to examine the expression of HIF-1 $\alpha$ and VEGF in human retinal pigment epithelial cells treated with ritonavir under hypoxic and normoxic conditions.
\end{abstract}

Methods ARPE-19 and D407 cells were cultured in normoxic or hypoxic conditions, alone or in the presence of ritonavir. Quantitative real-time polymerase chain reaction, immunoblot analysis, sandwich ELISA, endothelial cell proliferation, and cytotoxicity were performed.

Results A 12-h hypoxic exposure resulted in elevated mRNA expression levels of both HIF- $1 \alpha$ and VEGF in ARPE-19 and D407 cells. Hence, this time point was selected for subsequent experiments. Presence of ritonavir in the culture medium strongly inhibited VEGF expression in a concentration-dependent manner under hypoxic conditions. Immunoblot analysis demonstrated a substantially reduced protein expression of $\mathrm{HIF}-1 \alpha$ in the presence of ritonavir. Further, hypoxic exposureinduced VEGF secretion was also inhibited by ritonavir, as demonstrated using ELISA. Finally, ritonavir significantly diminished the proliferation of choroid-retinal endothelial (RF/6A) cells demonstrating
RK Vadlapatla, AD Vadlapudi, D Pal, M Mukherji and AK Mitra

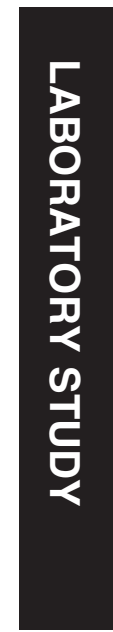

potential anti-angiogenic activity. Cytotoxicity studies showed that ritonavir is non-toxic to RPE cells.

Conclusions This study demonstrates for the first time that ritonavir can inhibit HIF-1 $\alpha$ and VEGF in ARPE-19 and D407 cells. Such inhibition may form a platform for application of ritonavir in the treatment of various ocular diseases.

Eye (2014) 28, 93-101; doi:10.1038/eye.2013.240; published online 8 November 2013

Keywords: hypoxia-inducible factor; vascular endothelial growth factor; ocular neovascularization; retinal pigment epithelial cells; drug repositioning; ritonavir

\section{Introduction}

The retina is the most metabolically active tissue and consumes more oxygen than any other tissue in the human body. ${ }^{1}$ Retinal hypoxia (oxygen deficiency) leading to angiogenesis is a major pathological condition underlying a number of sight-threatening diseases including diabetic retinopathy (DR), retinopathy of prematurity (ROP), age-related macular degeneration (AMD), and neovascular glaucoma. ${ }^{2,3}$ In response to hypoxia, retinal pigment epithelial (RPE) cells release various growth factors resulting in angiogenesis, fibro vascular tissue formation, retinal ablation, and ultimately loss of vision. This response is mediated via the transcriptional regulator hypoxia-inducible factor (HIF). It is a heterodimeric complex consisting of hypoxically stabilized subunit (HIF-1 $\alpha$ ) and stable nuclear subunit (HIF-1 $\beta /$ ARNT).
Division of Pharmaceutical Sciences, School of Pharmacy, University of Missouri-Kansas City, Kansas City, MO, USA

Correspondence: AK Mitra, University of Missouri Curators' Professor of Pharmacy, Chairman, Division of Pharmaceutical Sciences, Vice-Provost for Interdisciplinary Research, University of MissouriKansas City, School of Pharmacy, 2464 Charlotte Street, Kansas City, MO 64108-2718, USA. Tel: +1 816235 1615; Fax: +1 8162355779 . E-mail:mitraa@umkc.edu

Received: 27 July 2013 Accepted in revised form: 25 September 2013 Published online: 8 November 2013 
In normoxic conditions, HIF- $1 \alpha$ protein is rapidly hydroxylated on proline residues by 2-oxoglutaratedependent oxygenases. Post hydroxylation, von HippelLindau tumor suppressor protein (pVHL) marks HIF-1 $\alpha$ for E3 ubiquitin ligase-mediated proteosomal degradation. Under hypoxic conditions, hydroxylation is inhibited leading to nuclear translocation of HIF-1 $\alpha$ and subsequent dimerization with HIF-1 $\beta$. This transcriptionally active complex recruits several coactivators and modulates the gene expression of various target genes by binding to hypoxia response element (HRE). ${ }^{4-6}$

To date, more than 100 HIF target genes have been identified, many of which have a critical role in mediating angiogenesis, vascular tone, glucose and iron metabolism, cellular differentiation, invasion/metastasis, apoptosis and maintenance of stem cells. ${ }^{7-9}$ Few important target genes include vascular endothelial growth factor (VEGF), angiopoietin 2, platelet-derived growth factor-B (PDGF-B), placental growth factor (PGF), erythropoietin (EPO). ${ }^{10}$ Many investigations have demonstrated that VEGF is a common denominator promoting ocular angiogenesis. It is a predominant mitogen promoting vascular endothelial cell proliferation and migration. ${ }^{11,12}$ Currently available anti-VEGF therapeutics for the treatment of ocular neovascular diseases includes pegaptanib (Macugen, Valeant Pharmaceuticals, Bridgewater, NJ, USA), bevacizumab (Avastin, Genentech, Inc., South San Franscisco, CA, USA), ranibizumab (Lucentis, Genentech, Inc.), and aflibercept (Eylea, Regeneron Pharmaceuticals, Inc, Tarrytown, NY, USA). Pegaptanib is a 28-base RNA aptamer; bevacizumab is a humanized monoclonal antibody, whereas ranibizumab is an antibody-binding fragment of the former. All these molecules bind to secreted VEGF and prevent its interaction with VEGF receptors. ${ }^{13-15}$ Aflibercept is a recombinant fusion protein consisting of portions of VEGF receptors fused to Fc domain of IgG1. It acts as a soluble decoy receptor binding free VEGF. ${ }^{16}$ All these molecules are administered repeatedly at very high doses, and systemic side effects warrant their utility in the treatment of ocular diseases. ${ }^{17,18}$ Hence, therapeutic molecules that aim at inhibiting the signaling mechanisms underlying neovascularization (HIF-pathway) appear to have promising anti-angiogenic roles with fewer side effects.

Resurgent interest is directed toward identifying new implications of existing drugs rather than discovering new molecules. This process of drug repositioning can limit the associated cost and expedite the time required from bench to bedside transition of therapeutic molecules. Ritonavir, a HIV protease inhibitor, exhibits anti-neoplastic effects independent from its ability to inhibit HIV protease. ${ }^{19-21}$ Also, research has demonstrated that ritonavir can inhibit angiogenesis in Kaposi sarcoma, and head and neck carcinoma. ${ }^{22,23}$ However, the inhibitory potency of ritonavir on the HIF pathway and de novo synthesized VEGF in retinal tissues have not been so far investigated. Hence, the primary objective of this study was to investigate the expression of HIF- $1 \alpha$ and VEGF in human RPE cells (ARPE-19 and D407) treated with ritonavir under hypoxic and normoxic conditions. These results may assist in understanding the molecular mechanism of VEGF inhibition by ritonavir. Further, inhibition of VEGF via the HIF pathway may serve the possibility of using ritonavir in the treatment of various ocular angiogenic diseases.

\section{Materials and methods}

\section{Materials}

ARPE-19 and RF/6A cells were procured from American Type Culture Collection (ATCC; Manassas, VA, USA). D407 cells were obtained as a generous gift from Dr Richard Hunt (University of South Carolina). Ritonavir was obtained from Sigma Chemicals (St Louis, MO, USA). Dulbecco's Modified Eagle Medium (DMEM), DMEM/Nutrient Mixture F-12 (DMEM/F12), RPMI 1640, trypsin replacement (TrypLE Express), nonessential amino acids, TRIzol, and custom designed primers were purchased from Invitrogen (Carlsbad, CA, USA). Fetal bovine serum (FBS) was obtained from Atlanta Biologicals (Lawrenceville, GA, USA). Culture flasks (75 and $25 \mathrm{~cm}^{2}$ growth area) and 96-well plates $\left(0.3 \mathrm{~cm}^{2}\right.$ growth area per well) were procured from Corning Incorporated (Cambridge, MA, USA). The reagents for cDNA synthesis (OligodT, dNTP, M-MLV reverse transcriptase) and CellTiter 96 aqueous cell proliferation assay were supplied by Promega Corporation (Madison, WI, USA). Light Cycler 480 SYBR I green master mix was obtained from Roche Applied Science (Indianapolis, IN, USA). BCA protein assay reagent and human VEGF ELISA kit were purchased from Thermo Fisher Scientific Inc. (Rockford, IL, USA). Unless otherwise mentioned, all other chemicals were purchased from Sigma Chemicals and used without further purification.

\section{Cell culture}

ARPE-19 cells (passage numbers 25-30) were cultured in D-MEM/F-12 supplemented with 10\% FBS (heat inactivated), $15 \mathrm{mM}$ HEPES, $29 \mathrm{mM}$ sodium bicarbonate, $100 \mathrm{U} / \mathrm{ml}$ penicillin, and $100 \mu \mathrm{g} / \mathrm{ml}$ streptomycin. D407 cells (passage numbers 65-70) were maintained in DMEM medium supplemented with $10 \%$ FBS (heat inactivated), $1 \%$ nonessential amino acids, $20 \mathrm{mM}$ 
HEPES, $29 \mathrm{mM}$ sodium bicarbonate, $100 \mathrm{U} / \mathrm{ml}$ of penicillin and $100 \mu \mathrm{g} / \mathrm{ml}$ of streptomycin. RF/6A cells (passage numbers 5-10) were cultured using RPMI1640 supplemented with $10 \%$ FBS, $100 \mathrm{U} / \mathrm{ml}$ of penicillin, and $100 \mu \mathrm{g} / \mathrm{ml}$ of streptomycin. All the cells were maintained in a humidified atmosphere of $5 \% \mathrm{CO}_{2}$ and $90 \%$ relative humidity at $37^{\circ} \mathrm{C}$ in T-75 flasks. The medium was replaced every alternate day, and cells were passaged using TrypLE Express after reaching 80\% confluency. Cells were seeded at a density of 1 million cells in T-25 flasks. After reaching $\sim 80 \%$ confluency, cells were subjected to hypoxic conditions in a bactron anaerobic chamber with a special gas mix $\left(1 \% \mathrm{O}_{2}, 5 \% \mathrm{CO}_{2}\right.$ and $94 \%$ $\mathrm{N}_{2}$ ) for specified time periods following a previously published method. ${ }^{24}$ Cells cultured under hypoxic conditions were processed in the chamber itself to avoid any exposure to normoxic conditions.

\section{Extraction of RNA}

RNA was extracted using the standard phenolchloroform-isopropanol method. Briefly, cells were lysed in TRIzol reagent, and the lysate was transferred into an eppendorf tube. To facilitate phase separation, chloroform was added to lysate. The aqueous layer containing RNA was separated, and isopropanol was added to precipitate RNA. RNA pellet was washed twice with $75 \%$ ethanol and dissolved in DNase/RNase-free water. The concentration of RNA was estimated by detecting UV absorbance at $260 \mathrm{~nm}$ with Nanodrop (Thermo Fisher Scientific, Wilmington, DE, USA). Reverse transcription of RNA $(4 \mu \mathrm{g})$ into complementary DNA (cDNA) was carried out with OligodT as a template and M-MLV reverse transcriptase. The conditions for reverse transcription include denaturation for $5 \mathrm{~min}$ at $70{ }^{\circ} \mathrm{C}$, reverse transcription for $1 \mathrm{~h}$ at $42{ }^{\circ} \mathrm{C}$, and final extension for $5 \mathrm{~min}$ at $72{ }^{\circ} \mathrm{C}$.

\section{qPCR studies}

For quantitative gene expression analysis, $80 \mu \mathrm{g}$ of cDNA was amplified for specific genes with corresponding forward and reverse primers $(10 \mu \mathrm{M})$ and SYBR-green master mix using an ABI Prism 5700 Sequence Detection System (Applied Biosystems, Foster City, CA, USA). Primers were designed with Primer Blast tool from Pubmed (http://www.ncbi.nlm.nih.gov/tools/primer-blast /index.cgi?LINK_LOC=BlastHome). $\beta$-Actin was selected as an internal standard in all the samples. The sequences of the primers are as follows: $\beta$-actin forward 5'- GCATTGCTT TCGTGTAAATTATGT-3' reverse 5' - ACCAAAAGCCTTC ATACATCTCA-3'; HIF- $1 \alpha$ forward 5'-GTACCCTAACTAG CCGAGGAAGAA-3' reverse 5'-GTGAATGTGGCCTGTG CAGT-3'; VEGFA forward 5'- CTTGCCTTGCTGCTCTA C- $3^{\prime}$ reverse $5^{\prime}$-TGGCTTGAAGATGTACTCG-3'. The reactions were carried out with initial denaturation at $70{ }^{\circ} \mathrm{C}$ for $5 \mathrm{~min}$, followed by 45 cycles of denaturation at $95^{\circ} \mathrm{C}$ for $10 \mathrm{~s}$, annealing at $55^{\circ} \mathrm{C}$ for $10 \mathrm{~s}$, and extension at $72{ }^{\circ} \mathrm{C}$ for $10 \mathrm{~s}$. Melting curve analysis was used to check the specificity of PCR products. The relative fold mRNA expression in treated vs control samples was quantified by comparative threshold method as mentioned in data analysis section.

\section{Immunoblot analysis}

Following exposure to normoxic and hypoxic conditions, cells were washed with PBS $\left(3.2 \mathrm{mM} \mathrm{Na} \mathrm{HPO}_{4}, 0.5 \mathrm{mM}\right.$ $\mathrm{KH}_{2} \mathrm{PO}_{4}, 1.3 \mathrm{mM} \mathrm{KCl}$, and $135 \mathrm{mM} \mathrm{NaCl}$ ). Protein was extracted using radio immunoprecipitation assay (RIPA) buffer and protease inhibitor cocktail at $\mathrm{pH}$ 7.4. The amount of protein in the lysate was quantified using a BCA protein assay kit. An equal amount of protein $(20 \mu \mathrm{g})$ in all samples was separated using poly acrylamide gel electrophoresis (PAGE). The separated protein bands were transferred onto a polyvinylidene fluoride (PVDF) membrane and blocked for $2 \mathrm{~h}$ with $5 \%$ non-fat dry milk prepared in $0.05 \mathrm{M}$ tris-buffered saline. The blot was exposed overnight at $4{ }^{\circ} \mathrm{C}$ to the primary antibody (against HIF- $1 \alpha$ / or pAKT). After subsequent washes, the blot was exposed to the secondary antibody conjugated with horseradish peroxidase (HRP) for $2 \mathrm{~h}$. Finally, the blot was visualized for the protein of interest using chemiluminescent substrate in Chemilmager 8900 (Alpha Innotech, Santa Clara, CA, USA).

\section{Enzyme-linked immunosorbent assay}

The amount of VEGF secreted into the culture medium post exposure to normoxic or hypoxic conditions was estimated by performing a sandwich ELISA, following manufacturer's instructions. An anti-human $\mathrm{VEGF}_{165}$ antibody was precoated to the 96-well microplate. The samples/standards $(50 \mu \mathrm{l})$ were added to the antibodycoated wells and incubated for $2 \mathrm{~h}$. Unbound antigen was washed, followed by the addition of biotinylated secondary detecting antibody $(100 \mu \mathrm{l})$ and subsequent incubation for $1 \mathrm{~h}$. Excess detecting antibody was removed, and streptavidin-HRP was added. It reacts with TMB $\left(3,3^{\prime}, 5,5^{\prime}\right.$-tetramethylbenzidine $)$ substrate to produce a colorimetric signal. This signal was detected by measuring the absorbance at $450 \mathrm{~nm}$ using a plate spectrophotometer (SpectraFluor Plus, Maennedorf, Switzerland).

\section{Cell proliferation assay}

Relative proliferation of choroid-retinal endothelial cells (RF/6A) was determined using spent culture medium of ARPE-19 and D407 cells exposed to hypoxic or normoxic conditions, following a previously published method. ${ }^{25}$ 
Briefly, RF/6A cells were seeded in a 96-well plate at a density of 5000 cells per well. Following $24 \mathrm{~h}$ of seeding, cells were serum-starved overnight. Later, cells were treated for $24 \mathrm{~h}$ with medium collected from either normoxic or hypoxic conditions. Subsequently, solutions were aspirated, and $100 \mu \mathrm{l}$ of serum-free medium was added. Twenty microliters of MTS and PMS reagent was then added to wells. After incubating for $4 \mathrm{~h}$, the quantity of formazan formed from MTS was measured at $490 \mathrm{~nm}$ using a plate reader.

\section{Cytotoxicity assay}

A cytotoxicity assay was performed to determine the possible toxic effect of ritonavir on ARPE-19 and D407 cells. Briefly, RPE cells were seeded in a 96-well plate at a density of 10000 cells per well. Following $24 \mathrm{~h}$ of seeding, cells were exposed to either normoxic or hypoxic conditions in the absence or presence of three different concentrations of ritonavir for $12 \mathrm{~h}$. The solutions were aspirated, and cytotoxicity was determined using MTS and PMS reagents (CellTiter 96 aqueous cell proliferation) as described above.

\section{Data and statistical analysis}

Relative expression of each gene was quantified by deltadelta $(\Delta \Delta \mathrm{Ct})$ analysis following previously published method. ${ }^{26}$ All the experiments were performed in biological duplicates and experimental quadruplicates. Results were expressed as mean \pm standard deviation (SD). Statistical significance between experimental values was checked by performing one-way analysis of variance (ANOVA) or student's $t$-test (Graph Pad INSTAT, version 4.0, GraphPad Software, Inc., La Jolla, CA, USA). A $P$-value of $<0.05$ was considered to be statistically significant and represented by*.

\section{Results}

\section{Quantitative gene expression analysis}

Two RPE cell culture models (ARPE-19 and D407) were selected. Cells were exposed to normoxic and hypoxic conditions for 3,6 , and $12 \mathrm{~h}$. The quantitative gene expression levels of hypoxic master regulator (HIF-1 $\alpha$ ) and angiogenic stimulator (VEGF) were monitored. The expression of HIF- $1 \alpha$ did not change significantly following exposure of ARPE-19 cells for $3 \mathrm{~h}$ of hypoxic conditions. However, 6 and $12 \mathrm{~h}$ of hypoxic exposure induced the expression of HIF- $1 \alpha$ to almost two- and threefold, respectively. The expression of VEGF was significantly elevated by 2.5- to 6-fold upon hypoxic exposure from 3 to $12 \mathrm{~h}$ (Figure 1a). Three hours of hypoxic exposure did not alter the expression levels of both HIF- $1 \alpha$ and VEGF in D407 cells. A significant rise in
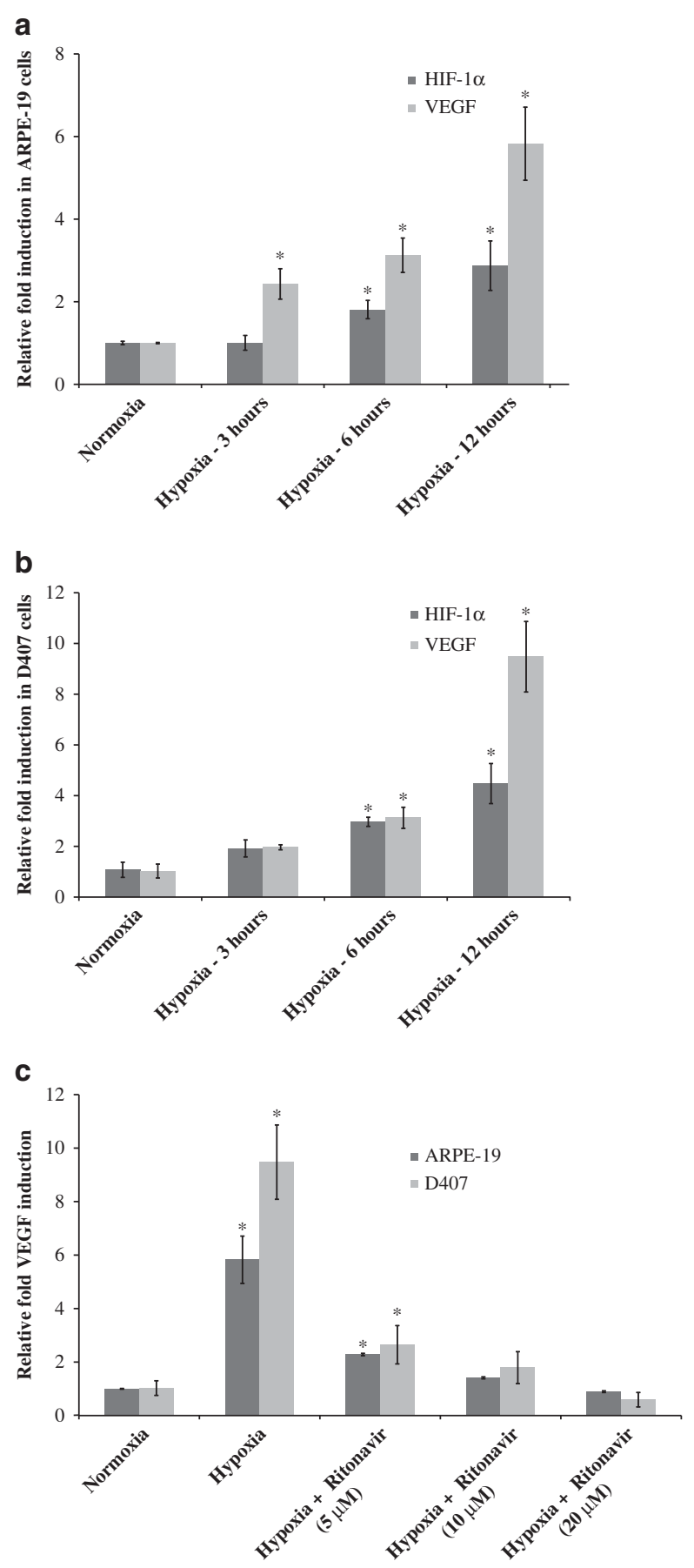

Figure 1 Relative fold mRNA expression of HIF- $1 \alpha$ and VEGF in (a) ARPE-19 and (b) D407 cells post exposure to 3, 6, and $12 \mathrm{~h}$ of hypoxia. (c) Relative fold mRNA expression of VEGF in ARPE-19 and D407 cells post exposure to hypoxia (12 h) in the absence or presence of three different concentrations of ritonavir $(5,10$, and $20 \mu \mathrm{M})$. Values are represented as mean \pm SD. A $P$-value of $<0.05$ was considered to be statistically significant from normoxia and represented by *. 
their expression was evident when cells were exposed to 6 and $12 \mathrm{~h}$ of hypoxia (Figure 1b). Among the three time points studied, hypoxic exposure to $12 \mathrm{~h}$ demonstrated significant elevation of HIF- $1 \alpha$ and VEGF mRNA expression levels in both cell lines. Hence, this time point was selected for all subsequent studies.

To evaluate if ritonavir can inhibit HIF- $1 \alpha$ and subsequent VEGF expression, cells were exposed to normoxic and hypoxic conditions in the presence or absence of ritonavir for $12 \mathrm{~h}$ and expression levels were monitored. Three different concentrations of ritonavir $(5,10$, and $20 \mu \mathrm{M})$ were selected. Ritonavir did not alter mRNA expression of HIF-1 $\alpha$ in both ARPE-19 and D407 cells (data not shown). Surprisingly, the presence of ritonavir strongly inhibited hypoxia-induced expression of VEGF in a concentration-dependent manner in ARPE19 cells. A similar trend was noticed even in D407 cells; ritonavir markedly reduced the expression of VEGF to basal levels (Figure 1c).

\section{Protein expression analysis}

Immunoblot analysis was performed to determine HIF-1 $\alpha$ protein expression levels. ARPE-19 and D407 cells were cultured for $12 \mathrm{~h}$ in normoxic or hypoxic conditions in the absence or presence of ritonavir. Total protein was extracted, electrophoresed, and detected using immunoblot analysis with a specific antibody. $\beta$-Actin was used as an internal loading control to normalize the protein expression in all samples. In ARPE-19 cells, the normoxic expression of HIF-1 $\alpha$ was negligible. HIF- $1 \alpha$ was not degraded following $12 \mathrm{~h}$ of hypoxic conditions. However, the presence of ritonavir $(10 \mu \mathrm{M})$ in hypoxic conditions significantly facilitated HIF- $1 \alpha$ protein degradation (Figure 2a). Similar results were also obtained in D407 cells. Exposure to hypoxia alone stabilized the expression of HIF-1 $\alpha$, whereas presence of ritonavir in hypoxic conditions facilitated HIF- $1 \alpha$ protein degradation (Figure $2 b$ ). Although ritonavir did not alter HIF- $1 \alpha$ mRNA expression, the protein expression was significantly diminished. This study suggests that ritonavir inhibits HIF- $1 \alpha$ synthesis at the translational level. Many signaling mechanisms including receptor tyrosine kinases, PI3K/Akt/mTOR, and Ras-MAPK pathways have a predominant role in HIF- $1 \alpha$ translation. Hence, an immunoblot analysis was performed to delineate the mechanism of HIF- $1 \alpha$ inhibition by ritonavir. Our preliminary study demonstrates that ritonavir decreased the level of Akt phosphorylation (at $\mathrm{Ser}^{473}$ ) in both ARPE-19 and D407 cells (Figures 2c and d).

\section{Estimation of VEGF by ELISA}

ARPE-19 and D407 cells were exposed to $12 \mathrm{~h}$ in normoxic or hypoxic conditions, either in the absence or
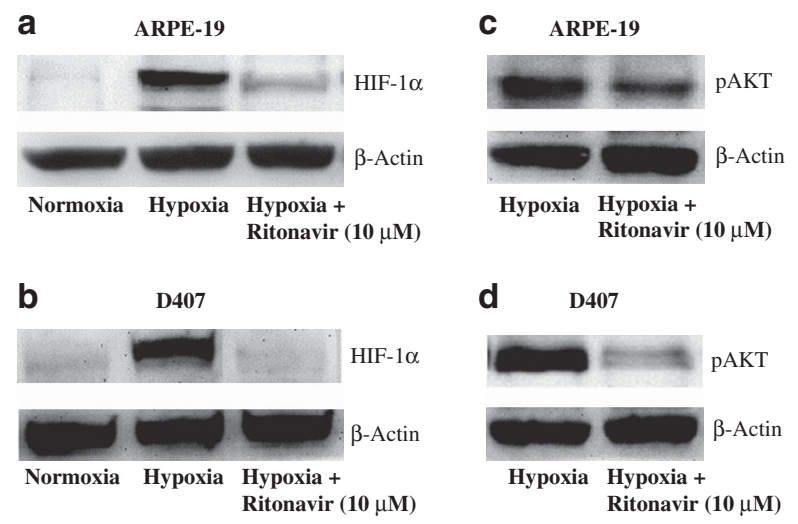

Figure 2 Immunoblot analysis showing the protein expression of (a) HIF- $1 \alpha$ in ARPE-19, (b) HIF- $1 \alpha$ in D407, (c) pAKT in ARPE19 , and (d) pAKT in D407 cells post exposure to hypoxia (12 h) in the absence or presence of ritonavir $(10 \mu \mathrm{M})$. $\beta$-Actin was used as an internal control.

presence of ritonavir $(5,10$ and $20 \mu \mathrm{M})$. The exposed culture media were collected and analyzed for concentration of VEGF secreted, using a sandwich ELISA method. This method was able to detect different VEGF concentrations varying from 31.25 to $2000 \mathrm{pg} / \mathrm{ml}$ with an estimated $R^{2}$ value (Pearson's coefficient) of 0.99 . Concentration of VEGF in ARPE-19 cells exposed to normoxic conditions was estimated to be $\sim 94 \mathrm{pg} / \mathrm{ml}$. Threefold rise in VEGF concentration was noticed in cells exposed to hypoxia. Interestingly, when cells were exposed to hypoxia in the presence of ritonavir, there was a concentration-dependent decrease in the amount of VEGF secreted (Figure 3a). A similar trend was also observed in D407 cells. Post exposure to hypoxic conditions, concentration of VEGF increased by twofold to $\sim 584 \mathrm{pg} / \mathrm{ml}$. However, VEGF secretion was inhibited by the presence of ritonavir in culture medium, suggesting that ritonavir inhibits VEGF production in hypoxic conditions (Figure 3b).

\section{Estimation of RF/6A cell proliferation}

RPE cells were cultured for $12 \mathrm{~h}$ in normoxic or hypoxic conditions, with or without ritonavir (5, 10 and $20 \mu \mathrm{M})$. The exposed culture media were collected, sterile filtered using $0.22-\mu \mathrm{m}$ syringe filters and tested for their ability to induce endothelial (RF/6A) cell proliferation. Following serum starvation, RF/6A cells were incubated with media from ARPE-19 and D407 cultures for $24 \mathrm{~h}$. Proliferation of endothelial cells was enhanced by 2.2 fold when treated with ARPE-19 hypoxic medium. However, ritonavir (10 and $20 \mu \mathrm{M})$ significantly inhibited this VEGF-induced proliferation (Figure 4a). Similarly, hypoxic culture medium of D407 cells also induced the proliferation of RF/6A cells by twofold. Compared with 

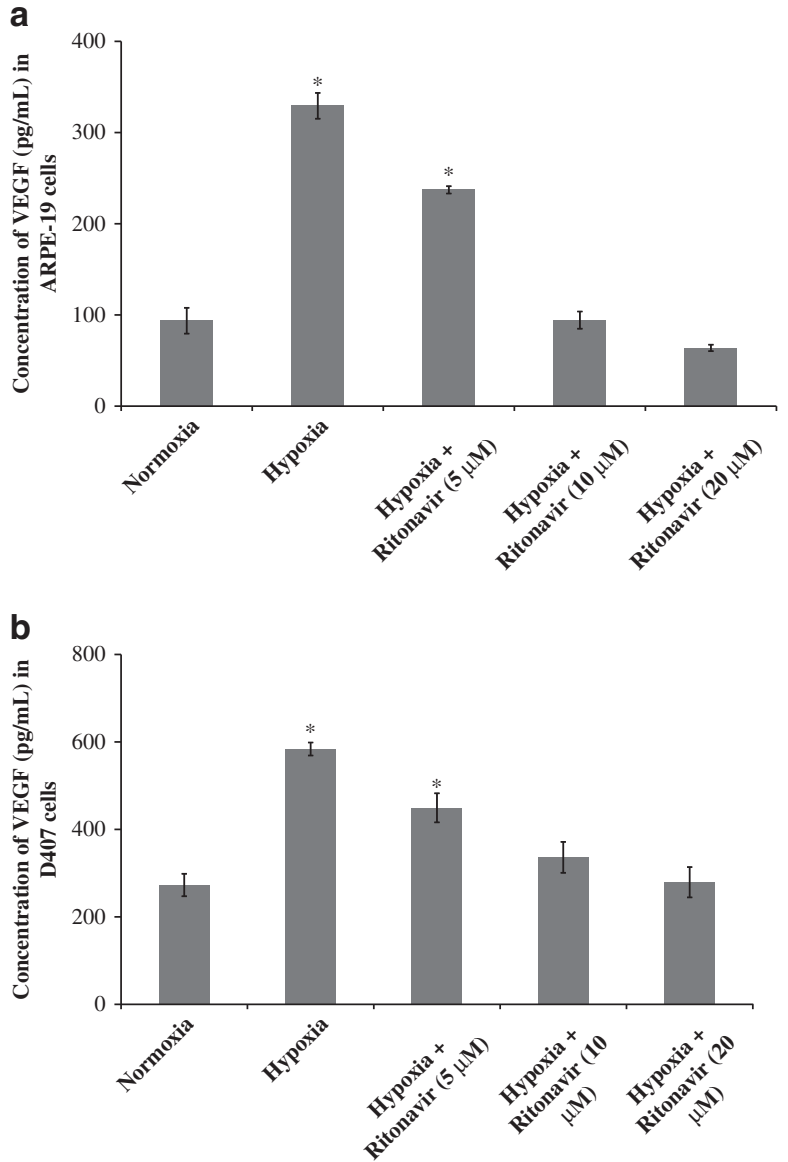

Figure 3 Sandwich ELISA assay measuring concentration of VEGF in (a) ARPE-19 and (b) D407 cell culture supernatant post exposure to hypoxia $(12 \mathrm{~h})$ in the absence or presence of ritonavir $(5,10$, and $20 \mu \mathrm{M})$. Values are represented as mean $\pm \mathrm{SD}$. A $P$-value of $<0.05$ was considered to be statistically significant from normoxia and represented by *.

the hypoxic group, cell proliferation was reduced in the presence of two concentrations of ritonavir tested (10 and $20 \mu \mathrm{M}$ ) (Figure 4b).

\section{Cytotoxicity assay}

MTS assay was performed to examine the possible cytotoxicity of various concentrations of ritonavir. All the three concentrations used were found to be non-cytotoxic to the RPE cells either under normoxia or hypoxia (Figures $5 \mathrm{a}$ and $\mathrm{b}$ ). This study suggests that any alterations in mRNA or protein expression levels are not attributed to drug toxicity.

\section{Discussion}

Ocular angiogenesis or formation of new blood vessels is a leading cause of ischemic retinopathies. It results from complex interplay between multiple gene products.
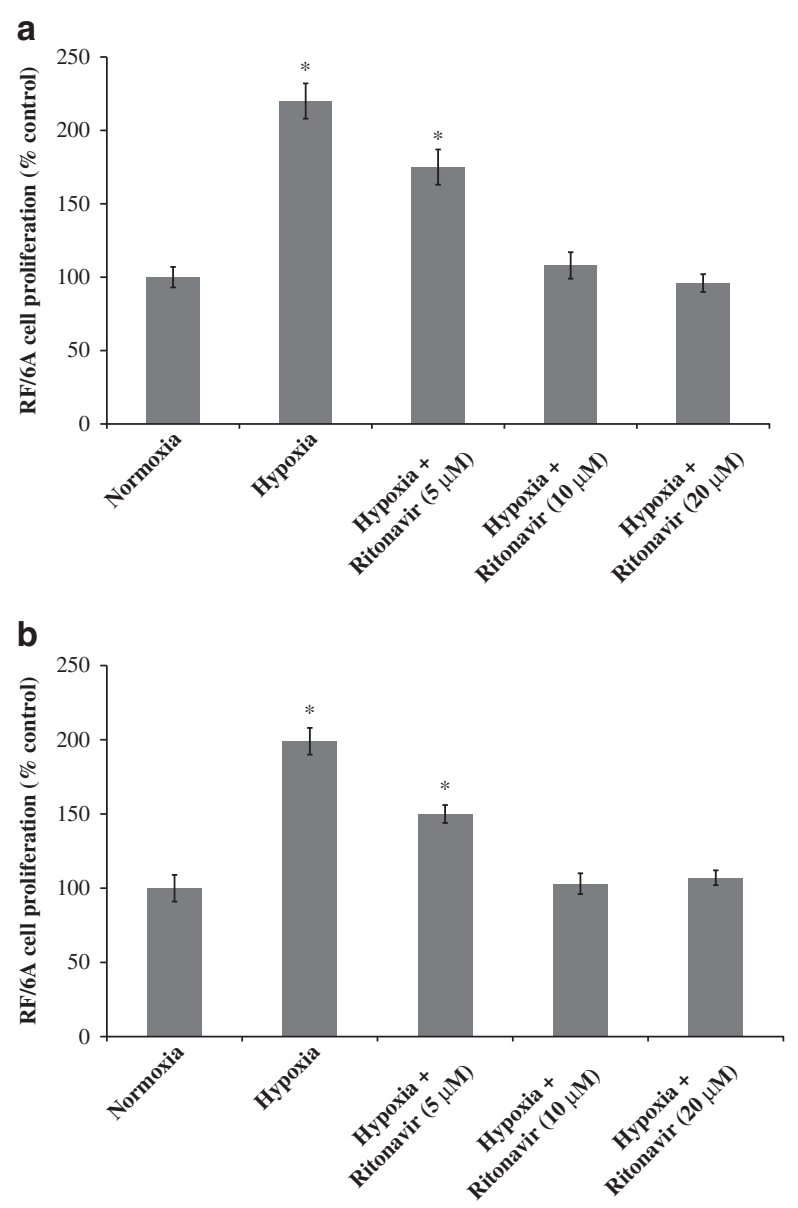

Figure 4 RF/6A cell proliferation with (a) ARPE-19 and (b) D407 spent cell culture media post exposure to hypoxia (12 h) in the absence or presence of ritonavir $(5,10$ and $20 \mu \mathrm{M})$. Values are represented as mean $\pm \mathrm{SD}$. A $P$-value of $<0.05$ was considered to be statistically significant from normoxia and represented by *.

Hypoxia or reduced oxygenation resulting in activation of HIF-1 was identified as a key transcriptional regulator of angiogenesis. ${ }^{27}$ In response to hypoxic conditions, HIF-1 induces transcription of many angiogenic stimulators in RPE cells. ${ }^{10,28}$ Current therapies aimed at treating ocular neovascular diseases include the utilization of large molecule therapeutics targeting VEGF. Although promising, long-term usage of such therapeutics is not free of side effects and must be considered with caution. Kurihara et al, have demonstrated the off-target effects resulting from specific knockout of Vegfa gene in adult mice. The knockout mice exhibited degeneration of choriocapillaris, dysfunction of cone photoreceptors, and ultimately vision loss. However, the transcriptional (HIF) mutants did not elicit any marked secondary off-target effects. ${ }^{29,30}$ These studies clearly reinforce that therapeutics aiming at the HIF pathway may be an alternative, safer, and effective 
mode of treatment than attenuating VEGF levels alone in the treatment of ocular neovascular diseases.

Significant research has been conducted in the past few years to identify inhibitors of the HIF pathway in RPE cells, which may provide better treatment for ischemic retinopathies. ${ }^{31-36}$ Although RNAi and many other small molecule inhibitors have been identified, their clinical translation is slow. Hence, interest is directed toward identifying new implications of existing drugs rather than discovering new molecules. This process of drug repositioning may expedite the clinical transition of therapeutic molecules. Ritonavir, a HIV protease inhibitor, exhibits anti-angiogenic, anti-proliferative, and anti-tumorigenic effects. Hence, ritonavir was evaluated for inhibition of HIF- $1 \alpha$ and VEGF in RPE cells, as this inhibition can provide therapeutic interventions for diseases caused by pathological neovascularization.

As RPE cells are an important source of angiogenic factors in retina, we selected two in vitro RPE models (ARPE-19 and D407). ${ }^{37}$ These cells have structural and functional characteristics similar to RPE cells and have been selected for studying the effects of hypoxia in RPE physiology. Hypoxic exposure for $12 \mathrm{~h}$ exhibited a significant rise in expression levels of HIF- $1 \alpha$ and VEGF in both ARPE-19 and D407 cells (Figure 1). When RPE cells were cultured in presence of three different concentrations of ritonavir, the mRNA expression of HIF-1 $\alpha$ remained unaltered (data not shown).

Interestingly, the expression of VEGF was inhibited in a concentration-dependent manner in the presence of ritonavir (Figure 1). However, in normoxic conditions the expression of VEGF remained unaltered in the presence of ritonavir (Supplementary Figure S1). This study clearly signifies that ritonavir inhibits VEGF expression via HIF-1 $\alpha$ signaling mechanism.

On the basis of their putative mechanism of action, HIF inhibitors may be classified as modulating RNA expression, protein translation, protein degradation, DNA binding activity, or transcriptional activity. ${ }^{2}$ Although ritonavir did not alter HIF- $1 \alpha$ mRNA expression, immunoblot analysis suggests that it significantly inhibited HIF- $1 \alpha$ protein translation (Figure 2). Our results corroborated with Pore et al, who demonstrated that nelfinavir, another HIV protease inhibitor, interfered with HIF- $1 \alpha$ protein translation in carcinoma cells. ${ }^{38}$ An active PI3K/Akt pathway is required for hypoxia-induced expression of HIF- $1 \alpha$ protein translation. ${ }^{39,40}$ Hence, a preliminary study was performed to analyze the levels of Akt in RPE cells post treatment with ritonavir. Our study indicates that ritonavir inhibits HIF- $1 \alpha$ protein translation via inhibition of Akt phosphorylation (Figure 2).

A major angiogenic stimulator in both physiological and pathological ocular conditions is VEGF. Although it exists as multiple isoforms due to alternative splicing, VEGF $_{165}$ has a vital role in augmenting vascular leakage and breakdown of blood retinal barrier. ${ }^{41}$ Our study has demonstrated that hypoxic RPE cells exhibited high levels of VEGF secretion. However, this hypoxia-induced secretion diminished significantly following treatment with ritonavir (Figure 3). This could possibly result from decreased HIF- $1 \alpha$ translation and subsequent VEGF transcription. The secreted VEGF modulates angiogenesis by inducing endothelial cell proliferation. ${ }^{42}$ To address anti-angiogenic activity of ritonavir, exposed RPE culture medium was used to assess the proliferation of choroid-retina endothelial (RF/6A) cells. Whereas proliferation of these cells increased significantly upon exposure to hypoxic medium, ritonavir inhibited such proliferation signifying its anti-angiogenic properties
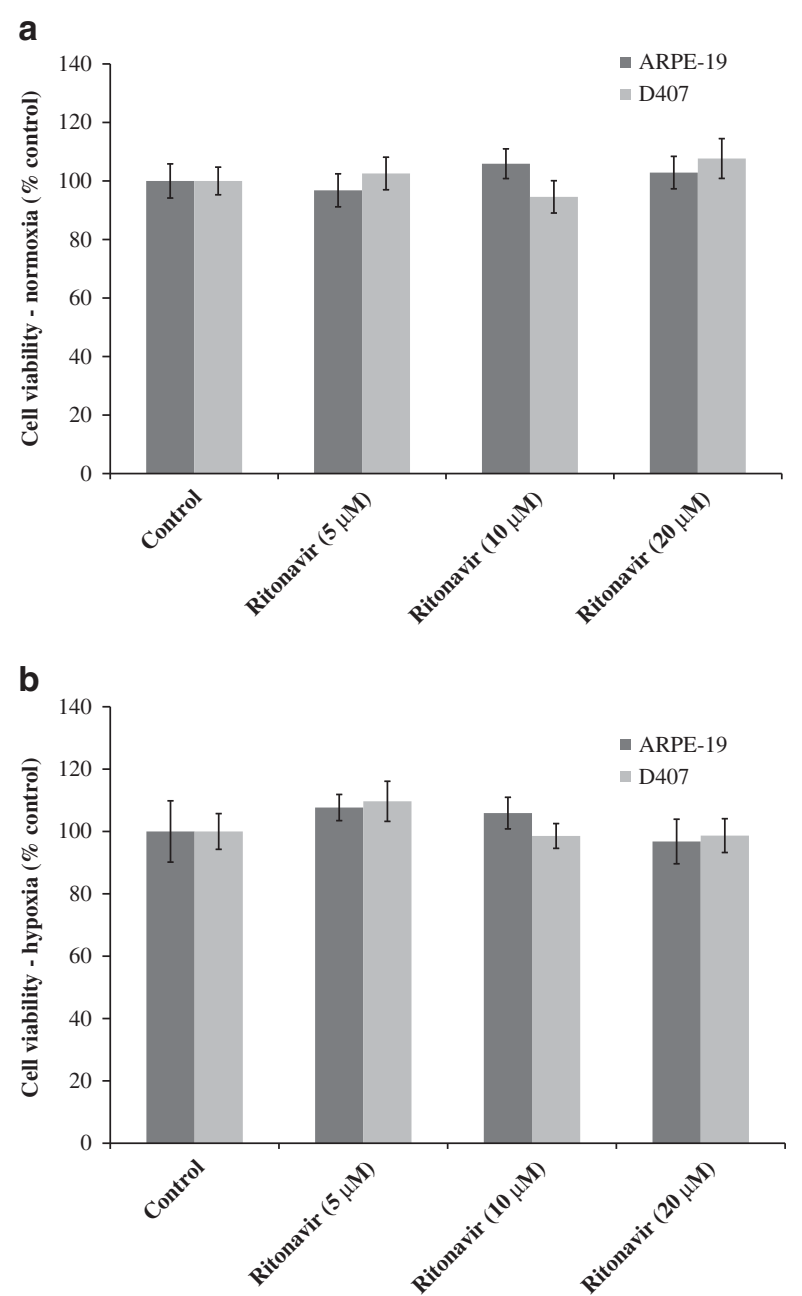

Figure 5 Cytotoxicity assay on ARPE-19 and D407 cells post exposure to (a) normoxia or (b) hypoxia (12 h) in the absence or presence of ritonavir $(5,10$, and $20 \mu \mathrm{M})$. Values are represented as mean $\pm S D$. 
(Figure 4). Cytotoxicity assay revealed that decreased HIF- $1 \alpha$ and VEGF expression is not due to RPE cell death (Figure 5).

Our studies have demonstrated that ritonavir inhibits the expression of HIF- $1 \alpha$-mediated VEGF expression in RPE cells probably via inhibition of the PI3K/Akt pathway (Supplementary Figure S2). This inhibition may reduce retinal neovascularization. These findings shed new light on the possibility of incorporating ritonavir in the treatment regimen of ocular angiogenic diseases. Although many inhibitors of HIF- $1 \alpha$ are in clinical trials, additional benefit of using ritonavir is that it has been given to HIV patients with relatively low toxicity. The process of traditional drug development could be fast tracked, as ritonavir is clinically approved for human use. However, further preclinical and clinical experiments are necessary to determine the repositioning of ritonavir in the treatment of ocular neovascular diseases.

\section{Summary}

What was known before

- The activation of HIF pathway leads to angiogenesis. Current anti-VEGF therapeutics pose significant longterm complications.

What this study adds

- Ritonavir inhibits HIF-mediated VEGF expression in retinal pigment epithelial cells. A novel therapeutic intervention for ocular neovascular diseases.

\section{Conflict of interest}

The authors declare no conflict of interest.

\section{Acknowledgements}

This research work has been supported by NIH Grants R01 EY09171-16 and R01 EY10659-14.

\section{References}

1 Kaur C, Foulds WS, Ling EA. Hypoxia-ischemia and retinal ganglion cell damage. Clin Ophthalmol 2008; 2(4): 879-889.

2 Vadlapatla RK, Vadlapudi AD, Mitra AK. Hypoxia-inducible factor-1 (hif-1): a potential target for intervention in ocular neovascular diseases. Curr Drug Targets 2013; 14(8): 919-935.

3 Caprara C, Grimm C. From oxygen to erythropoietin: relevance of hypoxia for retinal development, health and disease. Prog Retin Eye Res 2012; 31(1): 89-119.

4 Semenza GL. Hypoxia-inducible factors in physiology and medicine. Cell 2012; 148(3): 399-408.

5 Weidemann A, Johnson RS. Biology of HIF-1alpha. Cell Death Differ 2008; 15(4): 621-627.
6 Ke Q, Costa M. Hypoxia-inducible factor-1 (HIF-1) Mol Pharmacol 2006; 70(5): 1469-1480.

7 Rohwer N, Cramer T. Hypoxia-mediated drug resistance: novel insights on the functional interaction of HIFs and cell death pathways. Drug Resist Updat 2011; 14(3): 191-201.

8 Rankin EB, Giaccia AJ. The role of hypoxia-inducible factors in tumorigenesis. Cell Death Differ 2008; 15(4): 678-685.

9 Hewitson KS, Schofield CJ. The HIF pathway as a therapeutic target. Drug Discov Today 2004; 9(16): 704-711.

10 Campochiaro PA. Ocular neovascularization. J Mol Med 2013; 91(3): 311-321.

11 Ruas JL, Lendahl U, Poellinger L. Modulation of vascular gene expression by hypoxia. Curr Opin Lipidol 2007; 18(5): 508-514.

12 Conway EM, Collen D, Carmeliet P. Molecular mechanisms of blood vessel growth. Cardiovasc Res 2001; 49(3): 507-521.

13 Andriolo RB, Puga ME. Belfort Junior R, Atallah AN. Bevacizumab for ocular neovascular diseases: a systematic review. Sao Paulo Med J 2009; 127(2): 84-91.

14 Kourlas H, Abrams P. Ranibizumab for the treatment of neovascular age-related macular degeneration: a review. Clin Ther 2007; 29(9): 1850-1861.

15 Ng EW, Shima DT, Calias P, Cunningham Jr., ET, Guyer DR, Adamis AP. Pegaptanib a targeted anti-VEGF aptamer for ocular vascular disease. Nat Rev Drug Discov 2006; 5(2): 123-132.

$16 \mathrm{Xu}$ D, Kaiser PK. Intravitreal aflibercept for neovascular age-related macular degeneration. Immunotherapy 2013; 5(2): 121-130.

17 Slevin M, Kumar P, Wang Q, Kumar S, Gaffney J, Grau-Olivares $\mathrm{M}$ et al. New VEGF antagonists as possible therapeutic agents in vascular disease. Expert Opin Investig Drugs 2008; 17(9): 1301-1314.

18 Simo R, Hernandez C. Intravitreous anti-VEGF for diabetic retinopathy: hopes and fears for a new therapeutic strategy. Diabetologia 2008; 51(9): 1574-1580.

19 Srirangam A, Milani M, Mitra R, Guo Z, Rodriguez M, Kathuria $\mathrm{H}$ et al. The human immunodeficiency virus protease inhibitor ritonavir inhibits lung cancer cells, in part, by inhibition of survivin. J Thorac Oncol 2011; 6(4): 661-670.

20 Kumar S, Bryant CS, Chamala S, Qazi A, Seward S, Pal J et al. Ritonavir blocks AKT signaling, activates apoptosis and inhibits migration and invasion in ovarian cancer cells. Mol Cancer 2009; 8: 26

21 Srirangam A, Mitra R, Wang M, Gorski JC, Badve S, Baldridge $\mathrm{L}$ et al. Effects of HIV protease inhibitor ritonavir on Akt-regulated cell proliferation in breast cancer. Clin Cancer Res 2006; 12(6): 1883-1896.

22 Maggiorella L, Wen B, Frascogna V, Opolon P, Bourhis J, Deutsch E. Combined radiation sensitizing and antiangiogenic effects of ionizing radiation and the protease inhibitor ritonavir in a head and neck carcinoma model Anticancer Res 2005; 25(6B): 4357-4362.

23 Pati S, Pelser CB, Dufraine J, Bryant JL, Reitz Jr., MS, Weichold FF. Antitumorigenic effects of HIV protease inhibitor ritonavir: inhibition of Kaposi sarcoma. Blood 2002; 99(10): 3771-3779.

24 Ponnaluri VK, Vadlapatla RK, Vavilala DT, Pal D, Mitra AK, Mukherji M. Hypoxia induced expression of histone lysine demethylases: implications in oxygen-dependent retinal neovascular diseases. Biochem Biophys Res Commun 2011; 415(2): 373-377. 
25 Xu Y, Zhao H, Zheng Y, Gu Q, Ma J, Xu X. A novel antiangiogenic peptide derived from hepatocyte growth factor inhibits neovascularization in vitro and in vivo. Mol Vis 2010; 16: 1982-1995.

26 Vadlapatla RK, Vadlapudi AD, Ponnaluri VK, Pal D, Mukherji M, Mitra AK. Molecular expression and functional activity of efflux and influx transporters in hypoxia induced retinal pigment epithelial cells. Int J Pharm 2013; 454(1): 444-452.

27 Pugh CW, Ratcliffe PJ. Regulation of angiogenesis by hypoxia: role of the HIF system. Nat Med 2003; 9(6): 677-684.

28 Das A, McGuire PG. Retinal and choroidal angiogenesis: pathophysiology and strategies for inhibition. Prog Retin Eye Res 2003; 22(6): 721-748.

29 Quaggin SE. Turning a blind eye to anti-VEGF toxicities. I Clin Invest 2012; 122(11): 3849-3851.

30 Kurihara T, Westenskow PD, Bravo S, Aguilar E, Friedlander M. Targeted deletion of Vegfa in adult mice induces vision loss. J Clin Invest 2012; 122(11): 4213-4217.

$31 \mathrm{Oh}$ JH, Oh J, Togloom A, Kim SW, Huh K. Effects of Ginkgo biloba Extract on Cultured Human Retinal Pigment Epithelial Cells under Chemical Hypoxia. Curr Eye Res 2013; 38(10): 1072-1082.

32 Chen $\mathrm{P}$, Yin $\mathrm{H}$, Wang $\mathrm{Y}$, Xie L. Inhibition of VEGF expression and corneal neovascularization by shRNA targeting HIF1alpha in a mouse model of closed eye contact lens wear. Mol Vis 2012; 18: 864-873.

33 DeNiro M, Al-Halafi A, Al-Mohanna FH, Alsmadi O, Al-Mohanna FA. Pleiotropic effects of YC-1 selectively inhibit pathological retinal neovascularization and promote physiological revascularization in a mouse model of oxygen-induced retinopathy. Mol Pharmacol 2010; 77(3): 348-367.

34 Zhao W, Wang YS, Hui YN, Zhu J, Zhang P, Li X et al. Inhibition of proliferation, migration and tube formation of choroidal microvascular endothelial cells by targeting HIF-1alpha with short hairpin RNA-expressing plasmid DNA in human RPE cells in a coculture system. Graefes Arch Clin Exp Ophthalmol 2008; 246(10): 1413-1422.

35 Zhang $\mathrm{P}$, Wang $\mathrm{Y}$, Hui $\mathrm{Y}, \mathrm{Hu} \mathrm{D}$, Wang $\mathrm{H}$, Zhou J et al. Inhibition of VEGF expression by targeting HIF-1 alpha with small interference RNA in human RPE cells. Ophthalmologica 2007; 221(6): 411-417.

36 Wang B, Li H, Yan H, Xiao JG. Genistein inhibited hypoxia-inducible factor-1alpha expression induced by hypoxia and cobalt chloride in human retinal pigment epithelium cells. Methods Find Exp Clin Pharmacol 2005; 27(3): 179-184

37 Forooghian F, Razavi R, Timms L. Hypoxia-inducible factor expression in human RPE cells. Br J Ophthalmol 2007; 91(10): 1406-1410.

38 Pore N, Gupta AK, Cerniglia GJ, Jiang Z, Bernhard EJ, Evans SM et al. Nelfinavir down-regulates hypoxiainducible factor 1alpha and VEGF expression and increases tumor oxygenation: implications for radiotherapy. Cancer Res 2006; 66(18): 9252-9259.

39 Jacot JL, Sherris D. Potential Therapeutic Roles for Inhibition of the PI3K/Akt/mTOR Pathway in the Pathophysiology of Diabetic Retinopathy. J Ophthalmol 2011; 2011: 589813

40 Yang XM, Wang YS, Zhang J, Li Y, Xu JF, Zhu J et al. Role of PI3K/Akt and MEK/ERK in mediating hypoxia-induced expression of HIF-1alpha and VEGF in laser-induced rat choroidal neovascularization. Invest Ophthalmol Vis Sci 2009; 50(4): 1873-1879.

41 Witmer AN, Vrensen GF, Van Noorden CJ, Schlingemann RO. Vascular endothelial growth factors and angiogenesis in eye disease. Prog Retin Eye Res 2003; 22(1): 1-29.

42 Carmeliet P. Mechanisms of angiogenesis and arteriogenesis. Nat Med 2000; 6(4): 389-395.

Supplementary Information accompanies this paper on Eye website (http://www.nature.com/eye) 